\title{
Intestinal endometriosis: an uncommon cause of rectal bleeding
}

A 43-year-old woman was evaluated for hematochezia. The patient reported monthly episodes lasting 3 days, consisting of lower abdominal cramping and small amounts of bright red blood with every bowel movement. Her history was notable for uterine myomectomy.

Colonoscopy revealed a nonbleeding, rubbery, subepithelial mass in the rectum, measuring $1.5 \times 1.5 \mathrm{~cm}$, with a negative pillow sign ( Fig. 1). Follow-up endoscopic ultrasound (EUS) was serendipitously scheduled during her menstrual period and revealed patchy erythema on the surface of the mass ( Fig. 2). The muscularis propria appeared to be thickened and contiguous with the uterus ( $\bullet$ Fig. 3) leading to a diagnosis of rectal endometriosis. The patient was started on oral contraceptives (OCPs) and leuprolide, a gonadotrophin-releasing hormone $(\mathrm{GnRH})$ analog, with complete resolution of rectal bleeding.

Intestinal endometriosis is characterized by infiltration of the bowel wall by endometrial-like glands. Pathogenesis is believed to be secondary to retrograde passage and implantation of endometrial tissue in the peritoneum. These implants, which are regulated by hormones, can infiltrate and proliferate through the bowel wall [1]. The most common locations are the lower rectosigmoid colon, rectovaginal septum, and small intestine, with approximately a third of patients having multiple areas of involvement [2]. Symptoms can range from asymptomatic lesions to frank rectal bleeding. Because the intestinal mucosa is infrequently involved, cyclic bleeding is rare.

Unless patients have hematochezia at the time of evaluation, diagnosing intestinal endometriosis can be difficult. Colonoscopy is rarely helpful although other modalities, including ultrasound (transvaginal or endoscopic), computed tomography, and magnetic resonance imaging, may assist in diagnosis [3]. Laparoscopy with direct visualization and tissue sampling is confirmatory. Medical management consists of hormonal therapy (OCPs, GnRH agonists, and synthetic androgens) and is the standard approach for mild disease; severe cases may require surgery [4]. Although uncommon, intestinal endome-

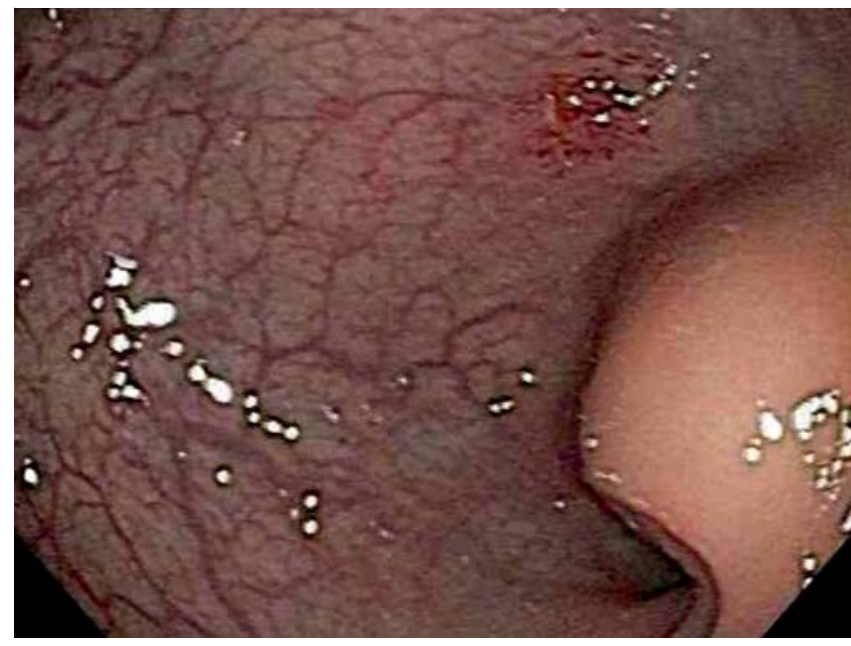

Fig. 1 Colonoscopy showing a rubbery, subepithelial rectal mass with a negative pillow sign. The mass was $1.5 \times 1.5 \mathrm{~cm}$ in size.

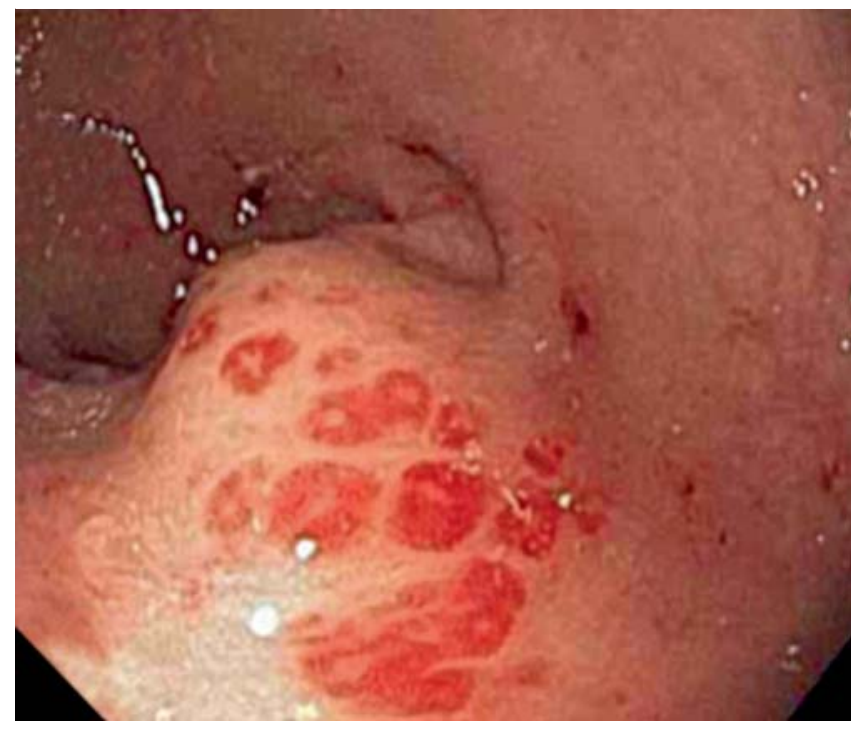

Fig. 2 Endoscopy carried out during menstrual period showing patchy mucosal erythema.

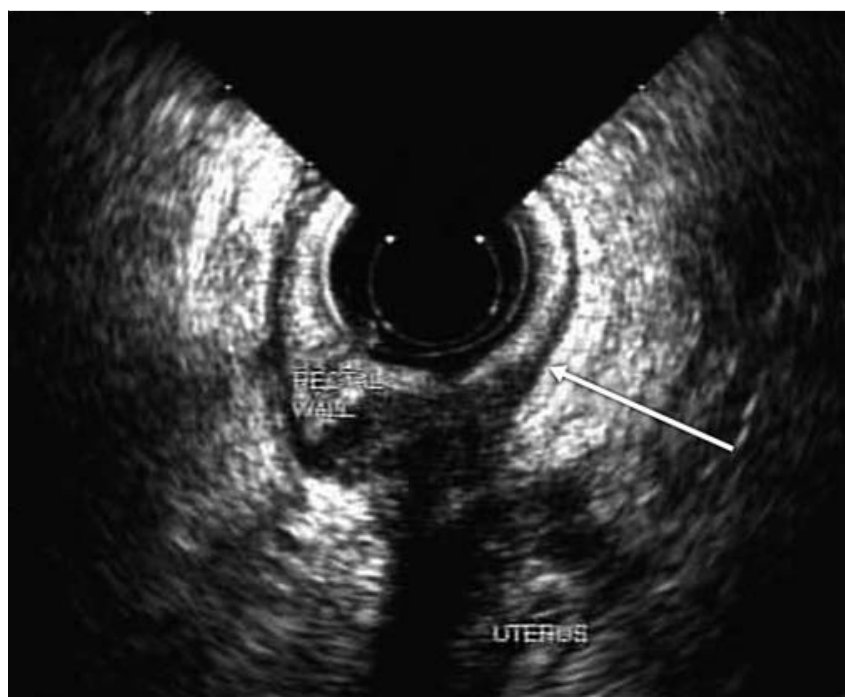

Fig. 3 Endoscopic ultrasound showing thickened muscularis propria apparently contiguous with the uterus (arrow). 
triosis is an important consideration in females of reproductive age presenting with rectal bleeding.

Endoscopy_UCTN_Code_CCL_1AD_2AC

\section{R. M. Kwok, F. J. Moawad, J. T. Laczek,} J. D. Horwhat

Gastroenterology Service, Walter Reed Army Medical Center, Washington DC, USA

\section{References}

1 Chapron C, Fauconnier A, Dubuisson JB et al. Deep infiltrating endometriosis: relation between severity of dysmenorrhoea and extent of disease. Hum Reprod 2003; 18: 760 766

2 Macafee $\mathrm{CH}$, Greer HL. Intestinal endometriosis. A report of 29 cases and a survey of the literature. J Obstet Gynaecol Br Emp 1960; 67: 539-555

3 Remorgida V, Ferrero S, Fulcheri E et al. Bowel endometriosis: presentation, diagnosis, and treatment. Obstet Gynecol Surv 2007; 62: $461-470$

4 Olive DL, Pritts EA. Treatment of endometriosis. N Engl J Med 2001; 345: 266 - 275
Bibliography

DOI $10.1055 / \mathrm{s}-0029-1243943$

Endoscopy 2010; 42: E112-E113

(c) Georg Thieme Verlag KG Stuttgart · New York . ISSN 0013-726X

\section{Corresponding author}

R. M. Kwok, MD

Department of Medicine

Walter Reed Army Medical Center

6900 Georgia Avenue

Washington DC 20307

USA

Fax: +1-202-782-4955

Ryan.Kwok@amedd.army.mil 